\title{
PET Imaging of Tumor Integrin Expression
}

\author{
Weibo Cai and Xiaoyuan Chen* \\ Molecular Imaging Program at Stanford (MIPS), Department of Radiology, Stanford \\ University School of Medicine, Stanford, CA 94305-5484 \\ Email: shawchen@stanford.edu
}

\begin{abstract}
The expression of integrin $\alpha_{v} \beta_{3}$ on sprouting capillary cells and their interaction with specific extracellular matrix ligands play a key role in tumor angiogenesis and metastasis. In several malignancies, tumor expression of integrin $\alpha_{v} \beta_{3}$ correlates well with tumor progression. Non-invasive imaging methods to visualize and quantify integrin $\alpha_{1} \beta_{3}$ expression in vivo are crucial for the success of anti-angiogenic therapy targeting integrin. Suitably labeled $R G D$ peptides (potent integrin $\alpha_{v} \beta_{3}$ antagonists) and antibodies have been developed for PET, SPECT and NIR fluorescence imaging of small animals. Due to the high sensitivity and adequate spatial and temporal resolution of PET, development of PET probes for integrin expression imaging has been the mainstay of active research. We improved the tumor targeting efficacy and in vivo pharmacokinetics by applying polyvalency effect and designed ${ }^{18} \mathrm{~F}$ - and ${ }^{64} \mathrm{Cu}$-labeled dimeric and multimeric RGD peptides for both imaging and imaging-guided internal radiotherapy applications.
\end{abstract}

\section{Introduction}

\section{Tumor angiogenesis and metastasis}

Angiogenesis, the formation of new blood vessels from pre-existing blood vessels, is a fundamental process occurring during tumor progression $[1,2]$. Like normal tissues, tumors require an adequate supply of oxygen, metabolites and an effective way to remove waste products. Gaining access to the host vascular system and generation of tumor blood supply is the rate-limiting step in tumor progression. Angiogenesis depends on the balance between pro-angiogenic molecules (VEGF, FGF, EGF, etc.) and antiangiogenic molecules (angiostatin, endostatin, etc.) $[3,4]$. The fact that tumors are dependent on blood supply has inspired many scientists to search for anti- angiogenic molecules, and to design anti-angiogenic strategies for cancer treatment and prevention of cancer recurrence and metastasis [5-7].

Tumor angiogenesis differs significantly from physiological angiogenesis. The differences include aberrant vascular structure, altered endothelial cellpericyte interactions, abnormal blood flow, increased permeability and delayed maturation [2,8,9]. Most tumors start growing as avascular nodules (dormant) until they reach a steady-state level of proliferating and apoptotic cells. Angiogenesis begins with perivascular detachment and vessel dilation, followed by angiogenic sprouting, new vessel formation and maturation, and the recruitment of perivascular cells. Blood-vessel formation continues as the tumor grows, feeding on hypoxic and necrotic areas of the tumor for essential nutrients and oxygen.

Cancer cells spread throughout the body by metastasis [10,11]. Both genetic and epigenetic changes contribute to cancer cells metastasis within a primary tumor. Metastasis occurs through several steps. First, cancer cells lose E-cadherin-dependent intercellular adhesions, acquire a migratory phenotype, detach from neighboring cells, penetrate the basement membrane and invade the interstitial matrix [12]. Second, tumor cells penetrate into blood vessels and lymphatic vessels and enter the circulatory system, a process called intravasation [13]. After reaching the bloodstream, tumor cells often adhere to platelets and leukocytes, forming emboli that stop in the microcirculation of target organs more easily than individual tumor cells [14]. Finally, metastatic cells exit the bloodstream (extravasation) and undergo expansive growth within the parenchyma of the target organ.

\section{Role of integrin during tumor progression}

Molecules regulating angiogenesis include growth factor receptors, tyrosine kinase receptors, G-proteincoupled receptors for angiogenesis modulating proteins, and integrins, a family of adhesion molecules 
consisting of two non-covalently bound transmembrane subunits ( $\alpha$ and $\beta$ ) [2-4]. Increasing amounts of evidence now imply that integrin signaling plays a key role in tumor angiogenesis and metastasis [15-17].

Efficient tumor invasion requires partial degradation of the extracellular matrix (ECM) at the invasion front. The matrix metalloproteinases (MMPs) are the major proteases involved in remodeling the ECM [12]. The $\alpha_{v} \beta_{3}$ integrin, which binds to ArginineGlycine-Aspartic acid (RGD)-containing components of the interstitial matrix, such as vitronectin, fibronectin and thrombospondin, is significantly upregulated on endothelium during angiogenesis but not in quiescent endothelium [17-19]. The special role of integrin $\alpha_{\mathrm{v}} \beta_{3}$ in tumor invasion and metastasis arises from its ability to recruit and activate MMP-2 and plasmin, which degrade components of the basement membrane and interstitial matrix [20]. Once integrin $\alpha_{\mathrm{v}} \beta_{3}$ is expressed, angiogenesis depends on it as antagonists of integrin $\alpha_{\mathrm{v}} \beta_{3}$ (antibodies, peptides and peptidomimetics) can inhibit tumor angiogenesis, tumor growth and metastasis in vivo $[15,16]$. Research has also shown that tumor expression of integrin $\alpha_{v} \beta_{3}$ correlates well with tumor progression in several malignancies such as melanoma [21], glioma [22], ovarian [23] and breast cancer [24,25].

\section{Integrin $\alpha_{v} \beta_{3}$ as the imaging target}

Conventional imaging modalities that detect anatomical and functional changes of tumor vascularity during angiogenesis, tumor growth and upon anti-angiogenic treatment provide little or no information regarding the specific molecular markers on newly formed blood vessels, tumor cells and the molecular changes upon therapy. Molecular imaging takes advantage of traditional diagnostic imaging techniques and introduces molecular imaging probes to determine the expression of indicative molecular markers of the tumor development at different stages [26-28].

For a targeting approach aimed at monitoring tumor angiogenesis and metastasis, the sufficient level of accessible tumor specific targets is a prerequisite for the lesion to be detectable and delineated from the background by imaging technologies. Integrin $\alpha_{\mathrm{v}} \beta_{3}$ serves as an excellent molecular marker for tumor angiogenesis and metastasis imaging. Interactions between vascular cells and ECMs are involved in multiple steps of angiogenesis [15,17,19]. Adhesion receptors of the integrin family are responsible for a wide range of cell-ECM and cell-cell interactions $[29,30]$. Each integrin molecule consists of noncovalently associated $\alpha$ and $\beta$ subunits, both type I membrane proteins with large extracellular segments that pair to create heterodimers with distinct adhesive capabilities [31,32]. In mammals, $18 \alpha$ and $8 \beta$ subunits assemble into 24 different receptors. The function of integrins during angiogenesis has been studied most extensively with $\alpha_{v} \beta_{3}$, which is not readily detectable in quiescent vessels but becomes highly expressed in angiogenic vessels $[15,16]$. Integrins expressed on endothelial cells modulate cell migration and survival during angiogenesis while integrins expressed on carcinoma cells potentiate metastasis by facilitating invasion and movement across blood vessels. Inhibition of $\alpha_{\mathrm{v}}$ integrin activity by monoclonal antibodies (mAbs), cyclic RGD peptide antagonists, and peptidomimetics has been shown to induce endothelial cell apoptosis [33], to inhibit angiogenesis [16], and to increase endothelial monolayer permeability [34].

The ability to non-invasively visualize and quantify integrin $\alpha_{\mathrm{v}} \beta_{3}$ expression level will provide new opportunities to document tumor (tumor cells and sprouting tumor vasculature) integrin expression, to more appropriately select patients for anti-integrin treatment and to monitor treatment efficacy in integrin-positive patients.

\section{Non-radionuclide imaging of integrin $\alpha_{v} \beta_{3}$ expression}

Over the last several years, research on integrintargeted molecular imaging has flourished. Contrastenhanced ultrasound using microbubbles targeting $\alpha_{\mathrm{v}^{-}}$ integrins expressed on the neovascular endothelium has been used to image tumor integrin status in addition to tumor microvascular blood volume and blood velocity, which can be easily detected with nontargeted microbubbles [35]. In an animal model, Sipkins et al. recently demonstrated the use of antibody-coated paramagnetic liposomes for MRI imaging of integrin $\alpha_{v} \beta_{3}$ expression [36]. However, due to the unfavorable physical characteristics of mAbs (vascularization requirements and barriers to antibody penetration, as well as intratumoral pressure) and low sensitivity of MRI, targeted MR imaging faces significant obstacles in providing a robust platform for tumor integrin assessment.

Recently, we and others have shown that nearinfrared (NIR) fluorescent dye Cy5.5 conjugated cyclic RGD peptide could be used to visualize subcutaneously inoculated integrin-positive tumors $[22,37]$. Since the major drawback of optical imaging is the limited penetration of light through tissue and skin, it has primarily been directed towards near surface lesions. Even though optical imaging may not 
be easily translated to human studies, NIR approach provides opportunities for rapid and cost-effective preclinical evaluation in small animal models before the more costly radionuclide-based imaging studies since in the NIR region $(700-900 \mathrm{~nm})$, the absorbance spectra for all biomolecules reach minima which provides a clear window for in vivo optical imaging [38].

\section{PET imaging of integrin $\alpha_{v} \beta_{3}$ expression}

To date, most of the studies have been focused on developing suitably radio-labeled RGD peptide antagonists of $\alpha_{\mathrm{v}}$-integrin as radiopharmaceuticals or molecular imaging probes for single-photon emission computed tomography (SPECT) and positron emission tomography (PET) [24,39-41]. For early lesion detection, acquisition of higher count statistics is particularly valuable for detecting the fewest possible cells per unit volume with the least amount of radioactivity. Due to the higher sensitivity of PET $\left(10^{-}\right.$ $\left.{ }^{11}-10^{-12} \mathrm{M}\right)$ as compared to SPECT $\left(10^{-9}-10^{-10} \mathrm{M}\right)$ $[42,43]$, development of PET imaging probes for integrin expression has been an area of intensive research. The crystal structures of extracellular segment of integrin $\alpha_{v} \beta_{3}$ and its complex with a potent cyclic peptide c(RGDf[NMe]V) (Cilengitide, Merck, Inc., currently in Phase II clinical trial) indicate that RGD binding site of integrin $\alpha_{v} \beta_{3}$ is located in the deep cleft between the two subunits [18]. The essential RGD sequence in this restrained conformation is well suited for development of high affinity and specific molecular imaging probes targeting integrin $\alpha_{v} \beta_{3}$. The current status of RGD-based PET probe development is reviewed in detail here.

\section{${ }^{18}$ F-labeled RGD peptides}

Monomeric RGD peptide c(RGDyV) was first labeled by Haubner et al. with ${ }^{125} \mathrm{I}$ [44]. This relatively lipophilic compound had rapid tumor washout and unfavorable hepatobiliary excretion. The resulting high liver and intestinal activity accumulation limited its further application. Glycosylation on the lysine side chain of a similar RGD peptide c(RGDyK) decreased the lipophilicity and consequently the hepatic uptake [45]. Another glycopeptide based on c(RGDfK) was then labeled with ${ }^{18} \mathrm{~F}$ via $2-\left[{ }^{18} \mathrm{~F}\right]$ fluoropropionate prosthetic group and the resulting $\left[{ }^{18} \mathrm{~F}\right]$ galacto-RGD (Figure 1) exhibited integrin $\alpha_{v} \beta_{3}$ specific tumor uptake in integrin-positive M21 melanoma xenograft model $[41,46,47]$. Initial clinical trials in healthy volunteers and a limited number of cancer patients revealed that this tracer can safely be administered to patients and is capable of delineating certain lesions that are integrin-positive [41]. Despite the initial success of this tracer in preclinical and clinical studies, several key issues remain to be resolved: 1) Tumor targeting efficacy. As a monomeric RGD peptide tracer, $\left[{ }^{18} \mathrm{~F}\right]$ galacto-RGD has relatively low integrin binding affinity and thus only moderate tumor SUV values; 2) Pharmacokinetics. Although glycosylation improved the pharmacokinetic behavior of an otherwise hydrophobic RGD peptide tracer, prominent activity accumulation in the kidneys, spleen, liver, and intestines was still observed in both preclinical animal models and human studies; 3) Quantification of integrin expression level. It is not clear whether the tumor contrast from $\left[{ }^{18} \mathrm{~F}\right]$ galacto-RGD/PET is a true reflection of tumor integrin $\alpha_{v} \beta_{3}$ expression level in vivo.

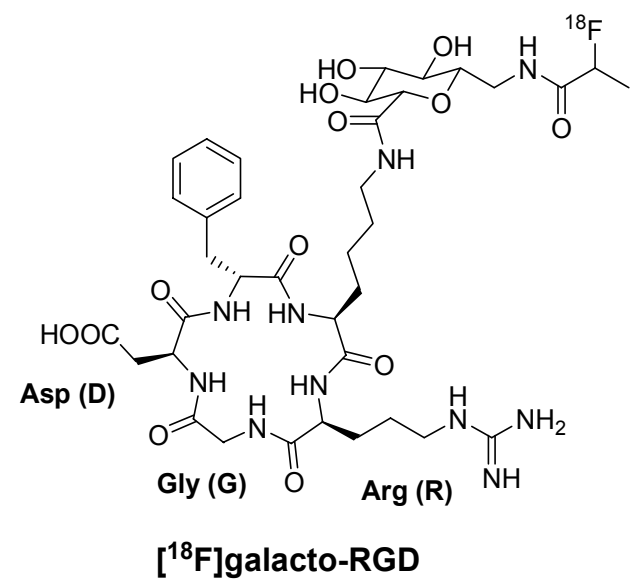

Figure 1. Structure of $\left[{ }^{18} \mathrm{~F}\right]$ galacto-RGD.

Sutcliffe-Goulden et al. also labeled a linear RGD peptide with ${ }^{18} \mathrm{~F}$ via solid-phase synthesis [48]. Unfortunately, low avidity and low metabolic stability of the linear RGD peptide failed to provide tumor contrast. Moreover, this seemingly facile solid-phase ${ }^{18} \mathrm{~F}$-labeling method is amenable to linear peptides but it would be difficult to apply to cyclic RGD peptides. RGD peptides have also been labeled with ${ }^{18} \mathrm{~F}$ through electrophilic substitution method [49]. The direct fluorination strategy resulted in multiple products which are difficult to purify by HPLC. The low specific activity of the carrier-added product, in particular, makes such tracers unsuitable for integrin imaging.

During the last few years, we have been focusing on the development of RGD-based probes for multimodality imaging of tumor integrin expression, including PET $\left({ }^{18} \mathrm{~F},{ }^{64} \mathrm{Cu},{ }^{86} \mathrm{Y}\right.$, and $\left.{ }^{124} \mathrm{I}\right)$, SPECT $\left({ }^{125} \mathrm{I}\right.$, ${ }^{99 \mathrm{~m}} \mathrm{Tc}$, and ${ }^{111} \mathrm{In}$ ), and NIR fluorescence (fluorescent dyes and biocompatible quantum dots). We initially labeled monomeric RGD peptide $\mathrm{c}(\mathrm{RGDyK})$ with ${ }^{18} \mathrm{~F}$ 
through a fluorobenzoyl prosthetic group (Figure 2) $[24,50,51]$. The resulting $\left[{ }^{18} \mathrm{~F}\right] \mathrm{FB}-\mathrm{RGD}$ had good tumor-to-blood and tumor-to-muscle ratios but also rapid tumor washout and unfavorable hepatobiliary excretion, making this relatively lipophilic tracer unsuitable for visualizing lesions in the lower abdomen.
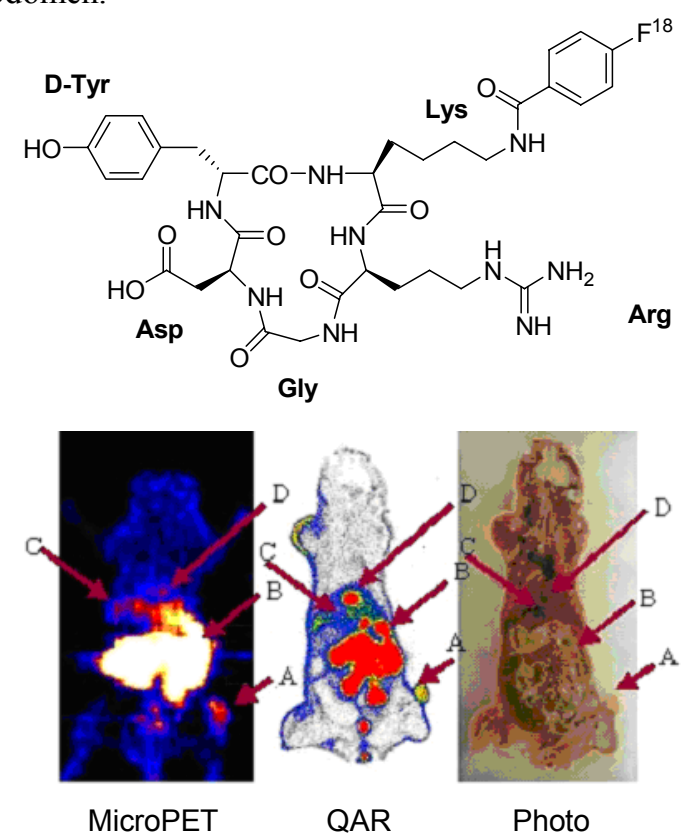

Figure 2. Top: Structure of $\left[{ }^{18} \mathrm{~F}\right] \mathrm{FB}-\mathrm{RGD}$. Bottom: Left, microPET scan (10 min single frame) obtained $30 \mathrm{~min}$ after injecting $200 \mu \mathrm{Ci}$ of $\left.{ }^{18} \mathrm{~F}\right] \mathrm{FB}-\mathrm{RGD}$ into a mouse carrying a U87MG glioblastoma xenograft on its right thigh; Middle, digital autoradiograph of the section containing tumor after microPET scanning; Right, an anatomic photograph of the section. (A: U87MG tumor; B: small intestines, C: liver; D: gallbladder)

Instead of introducing an amino sugar moiety to increase the hydrophilicity [41,46,47], we incorporated an amphiphilic poly(ethylene glycol) linker (PEG, $\mathrm{MW}=3,400)$ to improve the pharmacokinetics [51,52]. PEGylation significantly prolonged tumor retention without compromising the desirabe rapid clearance of radioactivity from liver and kidneys (Figure 3). Additionally, decreased biliary excretion minimized intestinal retention of the activity and increased tumor-to-background ratios. However, PEGylation also reduced the receptor binding affinity of the RGD peptide. The overall effect is that the tumor uptake is comparable to what is observed for the unmodified monomeric RGD peptide but with somewhat improved pharmacokinetics. Another disadvantage is that PEG is not a single species but rather a collection of molecules with an average molecular weight of 3,400 Da, which makes complete characterization of the tracer more difficult.
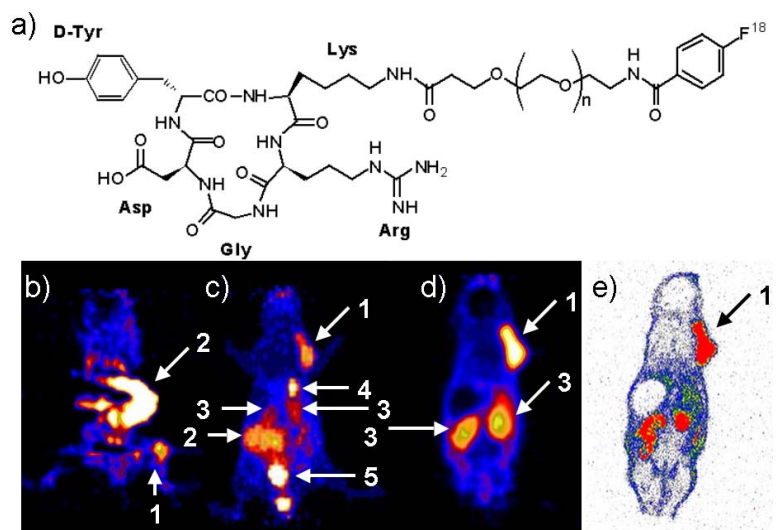

Figure 3. a) Structure of $\left[{ }^{18} \mathrm{~F}\right] \mathrm{FB}-\mathrm{PEG}-\mathrm{RGD}$. The heterobifunctional poly(ethylene glycol) linker has a molecular weight of $3,400 . \mathrm{b}$ ) Coronal microPET image of U87MG tumor-bearing mouse $30 \mathrm{~min}$ after injected $200 \mu \mathrm{Ci}$ of $\left[{ }^{18} \mathrm{~F}\right] \mathrm{FB}-\mathrm{RGD}$ (10 min static image). C) 2D projection of U87MG tumor-bearing mouse $60 \mathrm{~min}$ after injected $200 \mu \mathrm{Ci}$ of ${ }^{18} \mathrm{~F}$ FB-PEG-RGD (10 min static image). d) Coronal image of the mouse shown in c). e) Digital autoradiograph of the section containing tumor after microPET imaging. (1: U87MG tumor; 2: intestines; 3: kidney; 4: gallbladder and 5: bladder.)

Since $\mathrm{c}(\mathrm{RGDyK})$ in bent conformation has been optimized to fit into the deep cleft between the $\alpha$ and $\beta$ units of integrin $\alpha_{v} \beta_{3}$, it is very unlikely that one can further improve integrin affinity and selectivity of the monomeric RGD peptide by fine-tuning the pentapeptide configuration $[18,30]$. We thus applied polyvalency effect to develop dimeric and multimeric RGD peptides, with repeating cyclic pentapeptide units connected by glutamates. The dimeric RGD peptide $E[c(R G D y K)]_{2}$ with almost one order of magnitude higher binding affinity than the corresponding monomer $\mathrm{c}(\mathrm{RGDyK})$ was then labeled with $\quad{ }^{18} \mathrm{~F} \quad[25,53,54] . \quad\left[{ }^{18} \mathrm{~F}\right] \mathrm{FB}-\mathrm{E}[\mathrm{c}(\mathrm{RGDyK})]_{2}$ (abbreviated as $\left[{ }^{18} \mathrm{~F}\right]$ FRGD2) (Figure 4) showed predominant renal excretion and almost twice as much tumor uptake in the same animal model as compared to the monomeric tracer $\left[{ }^{18} \mathrm{~F}\right] \mathrm{FB}-\mathrm{c}(\mathrm{RGDyK})$. The synergistic effect of polyvalency and improved pharmacokinetics may be responsible for the excellent imaging characteristics of the dimeric RGD peptide tracer [55]. Furthermore, we have performed dynamic scans in several tumor xenograft models, including U87MG glioma, C6 rat glioma, MDA-MB-435 breast cancer, PC-3 prostate cancer, NCI-H1975 and A549 non-small cell lung cancers (Figure 5). Graphical analysis of the PET data (Logan plot [56]) which plots normalized integrated activity in the tumor vs. the normalized integrated activity in the muscle is shown in Figure 6. The graph becomes linear after 25-30 min post-injection (p.i.) where the slope represents distribution volume ratio (DVR). The binding 
potential (BP) which equals the concentration ratio of bond and free radioligand were 29.5, 17.5, 5.8, 4.1, 3.8, and 1.9, respectively (our unpublished data).

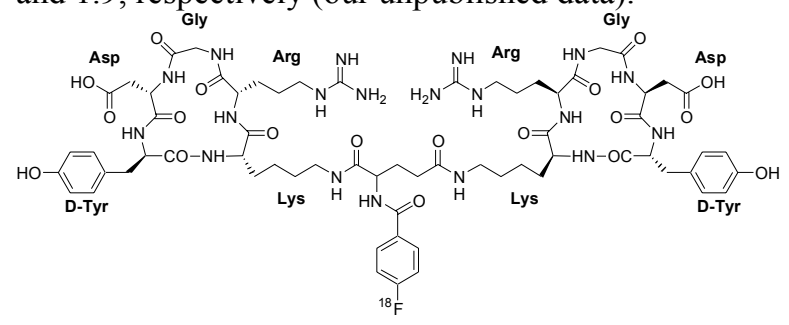

Figure 4. Structure of $\left[{ }^{18} \mathrm{~F}\right] \mathrm{FB}-\mathrm{E}[\mathrm{c}(\mathrm{RGDyK})]_{2}$.

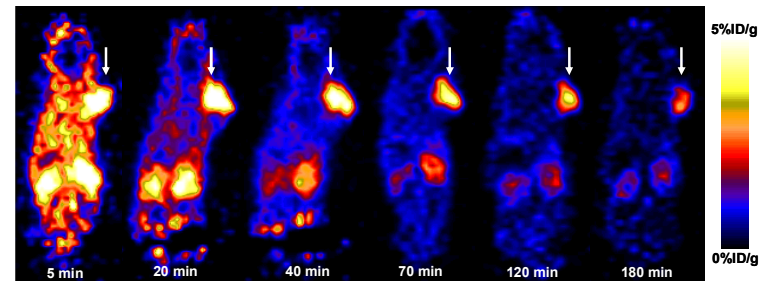

Figure 5. Dynamic microPET study of U87MG tumor bearing mouse over $60 \mathrm{~min}$ after injection of $\left[{ }^{18} \mathrm{~F}\right]$ FRGD2 $(100 \mu \mathrm{Ci})$, static scans at $2 \mathrm{~h}$ and $3 \mathrm{~h}$ time points were also conducted to complete the tracer kinetic study. Decay-corrected whole-body coronal images containing the tumor are shown (\%ID/g: percent injected dose per gram).

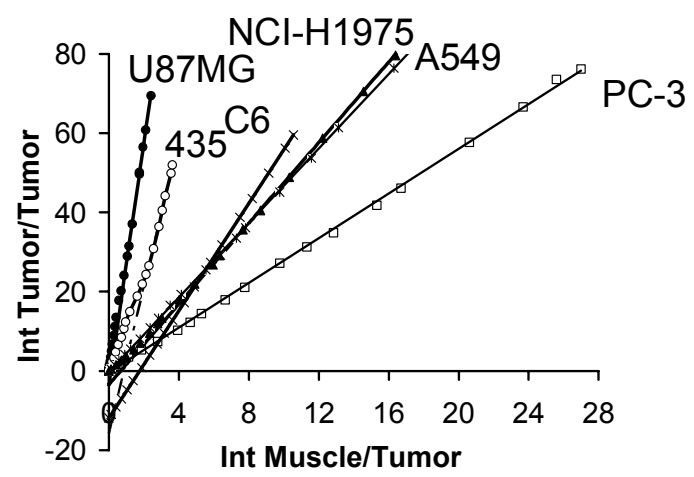

Figure 6. Logan plots derived from $60 \mathrm{~min}$ dynamic microPET imaging data, which showed excellent linearity of normalized integrated tumor activity versus normalized integrated muscle tissue activity for $\mathrm{t}>25$ $\min$. The slopes of the fits represent the distribution volume ratios (DVR).

Tumor-bearing mice were sacrificed after dynamic microPET imaging. The quantification of tumor integrin expression level was performed by incubating NP-40 solubilized tumor tissue lysate with ${ }^{125} \mathrm{I}$-echistatin in the presence of increasing concentrations of non-radiolabeled echistatin. After separation on SDS-PAGE, an autoradiograph was obtained and each radioactive band was subsequently quantified by a Phosphor Imager. Each competition curve was fitted by the Hill equation. The linear portion of the sigmoid curve was used to generate Scatchard transformation and $\mathrm{B}_{\max }$ (receptor number per mg protein) values were calculated. A representative autoradiograph of a competition experiment for U87MG glioma was shown in Figure 7 (our unpublished data). A good linear relationship was found between the BP values calculated from graphical analysis of the dynamic microPET data and the $\mathrm{B}_{\max }$ values measured from SDSPAGE/autoradiography, with the Pearson product moment correlation coefficient being 0.96 (Figure 8). This is the first report that one can quantify integrin expression in vivo by non-invasive PET imaging, which provides the basis for precise documentation of tumor integrin levels without biopsy. Estimation of human radiation dosimetry from the mouse and rat biodistribution data found that the effective dose for an $\left[{ }^{18} \mathrm{~F}\right] \mathrm{FRGD} 2$ scan is in the same range as for an $\left[{ }^{18} \mathrm{~F}\right] \mathrm{FDG}$ scan, an approved routine examination tracer in the clinic.

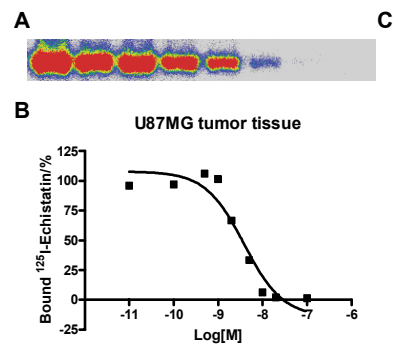

C

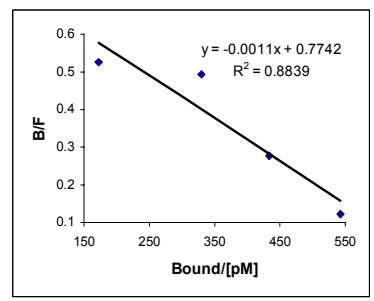

Figure 7. Analysis of U87MG tumor tissue integrin level by SDS-PAGE/autoradiography. NP-40 solubilized tumor tissue lysate $(30 \mu \mathrm{g})$ was incubated with $1 \times 10^{5} \mathrm{cpm}{ }^{125}$ I-echistatin for $2 \mathrm{~h}$ and increasing concentrations of echistatin. After separation on $0.6 \%$ SDS-PAGE, an autoradiograph was obtained (A) and each radioactivity band was quantified by a Phosphor Imager (B). Scatchard transformation (C) of the sigmoid curve gives tissue receptor density (receptor number per mg tissue).

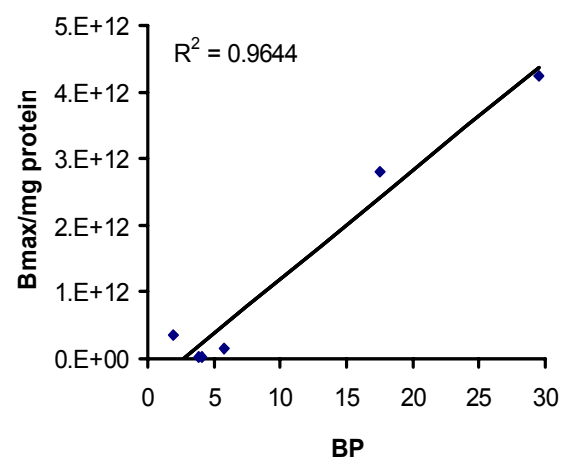

Figure 8. Correlation analysis between tumor cell receptor density (measured from SDSPAGE/autoradiography) and binding potential (BP) 
(calculated from Logan plot transformation of dynamic microPET imaging data) of various tumor models exhibited excellent linear relationship $\left(R^{2}=0.96\right)$.

\section{${ }^{64} \mathrm{Cu}$-labeled RGD Peptides}

For PET imaging of integrin $\alpha_{v} \beta_{3}$ expression, ${ }^{18} \mathrm{~F}$ labeled RGD peptides will be the first choice, since $\left[{ }^{18} \mathrm{~F}\right] \mathrm{F}^{-}$is readily available from most medical cyclotron facilities, and radiolabeling of peptides with ${ }^{18} \mathrm{~F}$ can be readily achieved by introducing a prosthetic group. In addition to ${ }^{18} \mathrm{~F}$-labeled RGD peptides, ${ }^{64} \mathrm{Cu}$ and ${ }^{86} \mathrm{Y}$-labeled RGD peptides are of considerable interest. ${ }^{64} \mathrm{Cu}\left(\mathrm{t}_{1 / 2}=12.7 \mathrm{~h} ; \beta^{+}=655 \mathrm{keV}[19 \%] ; \beta^{-}=\right.$ $573 \mathrm{keV}[40 \%]$ ) is an attractive radionuclide for both PET imaging and targeted radiotherapy of cancer [57] while ${ }^{86} \mathrm{Y}\left(\mathrm{t}_{1 / 2}=14.7 \mathrm{~h}\right)$ is usually used as a substitute of ${ }^{90} \mathrm{Y}$ for pharmacokinetics and dosimetry studies [58]. PET imaging of tumors with low doses of ${ }^{64} \mathrm{Cu}$ labeled RGD peptides could also be utilized to determine individual radiation dosimetry prior to therapy with either high dose ${ }^{64} \mathrm{Cu}$ - or ${ }^{67} \mathrm{Cu}$-labeled RGD peptides. ${ }^{64} \mathrm{Cu}$ labeling is also fairly straightforward and amenable for kit formulation.

We initially labeled the DOTA-c(RGDyK) conjugate with ${ }^{64} \mathrm{Cu}$ for breast cancer imaging (Figure 9). The radiotracer showed intermediate tumor uptake but also prominent liver and kidney retention [24]. The PEGylated analog, ${ }^{64} \mathrm{Cu}$-DOTA-PEG-c(RGDyK), on the other hand, had significantly reduced hepatic activity accumulation, as compared with ${ }^{64} \mathrm{Cu}$-DOTA$\mathrm{c}(\mathrm{RGDyK})$ [40]. The PEGylated tracer had higher renal uptake than ${ }^{64} \mathrm{Cu}$-DOTA-c(RGDyK) at early time points but more rapid clearance as time elapsed. Although introduction of PEG at the lysine side chain amino group somewhat reduced the integrin binding affinity of the RGD peptide, the tumor activity accumulation was virtually unaltered. In spite of the high tumor contrast and favorable in vivo kinetics, the sub-optimal tumor uptake and retention of the PEGylated tracer limited its further application for receptor radionuclide therapy.

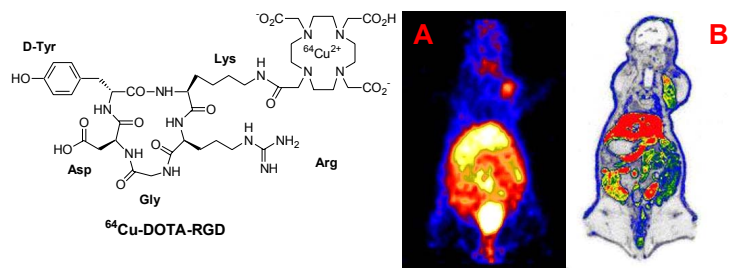

Figure 9. (A) MicroPET scan of mouse injected with $400 \mu \mathrm{Ci}$ of ${ }^{64} \mathrm{Cu}$-DOTA-RGD and scanned $2 \mathrm{~h}$ later (15 min single frame). The mouse carried an orthotopic MDA-MB-435 breast cancer xenograft in the right mammary fat pad. (B) Digital autoradiograph of the section containing tumor.
We have also labeled dimeric RGD peptides with ${ }^{64} \mathrm{Cu}$ and ${ }^{86} \mathrm{Y}$ and tested their tumor targeting efficacy in murine xenograft models. At all time points, activity accumulation of ${ }^{64} \mathrm{Cu}-\mathrm{DOTA}-\mathrm{E}[\mathrm{c}(\mathrm{RGDyK})]_{2}$ in tumors was significantly higher than that of the DPhe analog [25]. Liver uptake of the D-Tyr derivative c(RGDyK) was lower than the D-Phe derivative c(RGDfK) at early time points but the difference became marginal over time. Overall, ${ }^{64} \mathrm{Cu}$-DOTA$\mathrm{E}[\mathrm{c}(\mathrm{RGDyK})]_{2}$ yielded better PET images in orthotopic MDA-MB-435 bearing mice than did ${ }^{64} \mathrm{Cu}$ DOTA-E[c(RGDfK) $]_{2}$, most likely due to the increased hydrophilicity of the D-Tyr. Both dimeric peptides showed better tumor retention than the previously tested monomeric RGD counterparts, presumably because of bivalency and increase in apparent molecular size. We have also demonstrated that the tumor uptake can be efficiently blocked by injection of unlabeled RGD peptide (Figure 10) [25].

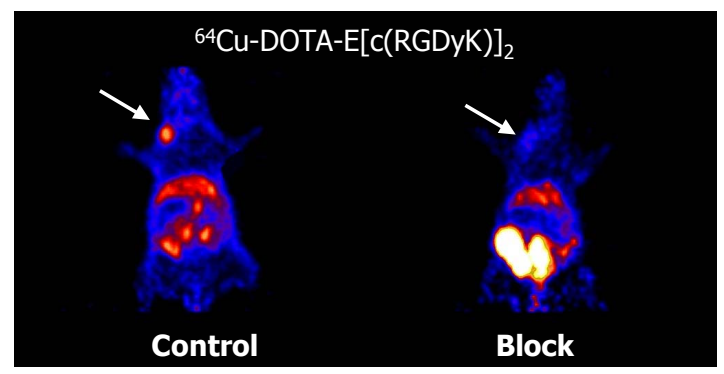

Figure 10. Coronal microPET images (15 min single frame) of MDA-MB-435 tumor-bearing athymic nude mice $2 \mathrm{~h}$ after injected $400 \mu \mathrm{Ci}$ of ${ }^{64} \mathrm{Cu}$-DOTA$\mathrm{E}[\mathrm{c}(\mathrm{RGDyK})]_{2}$, with (left) and without (right) a coinjected blocking dose of $c(R G D y K)(15 \mathrm{mg} / \mathrm{kg})$.

PEGylated RGD dimer ${ }^{64} \mathrm{Cu}$-DOTA-PEG$\mathrm{E}[\mathrm{c}(\mathrm{RGDyK})]_{2}$ had similar blood clearance, more rapid renal clearance, and significantly reduced hepatic uptake compared with ${ }^{64} \mathrm{Cu}$-DOTA$\mathrm{E}[\mathrm{c}(\mathrm{RGDyK})]_{2}[53]$. However, tumor uptake was also lowered due to the fact that the PEGylated RGD dimer had lower receptor binding affinity than the dimeric RGD peptide. Rapid tumor localization with relatively low normal tissue uptake outside the gut makes ${ }^{64} \mathrm{Cu}-$ DOTA-PEG-E[c(RGDyK) $]_{2}$ a promising agent for tumor imaging. One striking observation is that PEGylated dimeric RGD peptide tracer accumulated more specifically in both primary and metastatic lung tumor lesions than FDG, which only delineates the primary tumor but none of the metastatic sites (data not shown) since FDG uptake is not tumor specific which gives very high background in the heart and the abdomen (Figure 11). However, the significance of this finding may be slightly diluted by the fact that the 
magnitude of tumor uptake is too low (less than 3 $\% \mathrm{ID} / \mathrm{g}$ ) for peptide receptor radiotherapy (PRRT) applications [53].
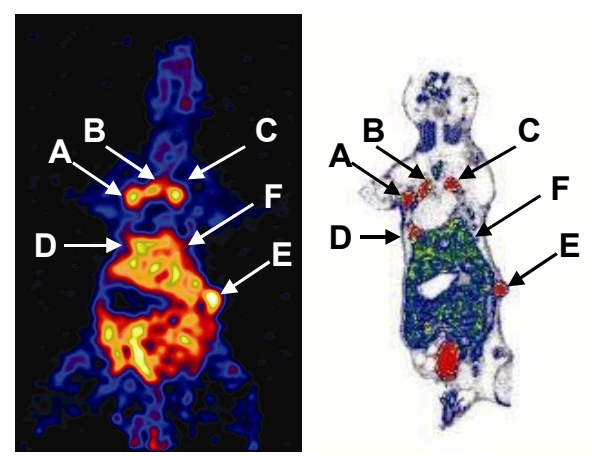

Figure 11. Left: coronal image (15 min static scan) of SCID-bg mouse bearing both subcutaneous and orthotopic NCl-H1975 tumors at $2 \mathrm{~h}$ after injected 300 $\mu \mathrm{Ci}$ of ${ }^{64} \mathrm{Cu}-\mathrm{DOTA}-\mathrm{PEG}-\mathrm{E}[\mathrm{c}(\mathrm{RGDyK})]_{2}$. Both primary tumors and metastases are clearly identified. Right: whole body digital autoradiograph of a $50 \mu \mathrm{m}$ thick section correlating well with the coronal microPET image shown on the left. A: primary orthotopic tumor in the upper lobe of the left lung; B: local metastasis of the primary tumor; C: contralateral lung metastasis; D: metastasis in the diaphragm; E: subcutaneous tumor; F: liver.

Very recently, we developed a tetrameric RGD peptide tracer ${ }^{64} \mathrm{Cu}$-DOTA-E $\left\{\mathrm{E}[\mathrm{c}(\mathrm{RGDfK})]_{2}\right\}_{2}$ (Figure 12) for imaging of integrin $\alpha_{\mathrm{v}} \beta_{3}$ expression in a subcutaneous U87MG glioma xenograft model [59].

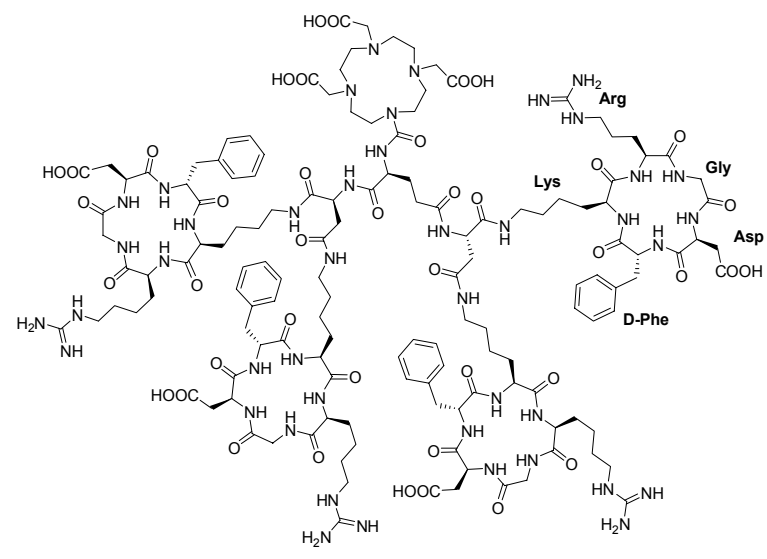

Figure 12. Structure of DOTA-E $\left\{E[c(R G D f K)]_{2}\right\}_{2}$. The tetrameric RGD peptide was synthesized by coupling Boc-Glu(OSu)-OSu with dimeric RGD peptide $\mathrm{E}[\mathrm{c}(\mathrm{RGDfK})]_{2}$ followed by removal of Boc protecting group. DOTA conjugation was achieved by reacting monoactive ester of DOTA with the free amino group on the $\mathrm{N}$-terminal glutamate.

The RGD tetramer showed significantly higher integrin binding affinity than the corresponding monoand dimeric RGD analogs (Figure 13). The radiolabeled peptide showed rapid blood clearance and predominant renal excretion. Tumor uptake was rapid and high, and the tumor washout was slow (9.93 \pm $1.05 \% \mathrm{ID} / \mathrm{g}$ at $30 \mathrm{~min}$ p.i. and $4.56 \pm 0.51 \% \mathrm{ID} / \mathrm{g}$ at 24 h p.i.). This tracer was also metabolically stable. Noninvasive microPET imaging studies showed significant receptor-mediated tumor uptake and good contrast in tumor mice. The high integrin avidity and favorable biokinetics make ${ }^{64} \mathrm{Cu}-\mathrm{DOTA}-\mathrm{E}\left\{\mathrm{E}[\mathrm{c}(\mathrm{RGDfK})]_{2}\right\}_{2}$ a promising agent for peptide receptor radionuclide imaging as well as radiotherapy of integrin-positive tumors.

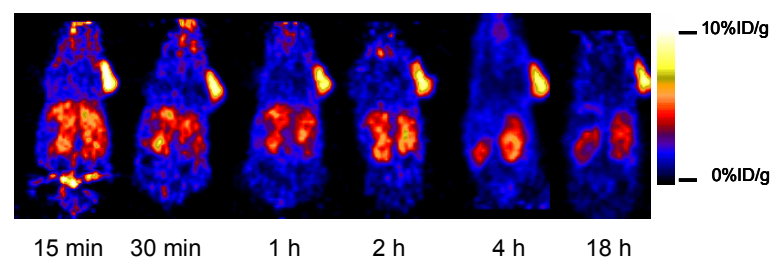

Figure 13. Decay-corrected whole-body coronal microPET images of a nude mouse bearing human U87MG tumor at $15 \mathrm{~min}, 30 \mathrm{~min}, 1 \mathrm{~h}, 2 \mathrm{~h}, 4 \mathrm{~h}$ and $18 \mathrm{~h}$ (10 min static image) after injected $245 \mu \mathrm{Ci}$ of ${ }^{64} \mathrm{Cu}$ DOTA-E $\left\{E[c(R G D f K)]_{2}\right\}_{2}$.

\section{Conclusion and future perspective}

Significant advances have been achieved in developing PET probes for imaging tumor integrin $\alpha_{v} \beta_{3}$ expression. ${ }^{18} \mathrm{~F}$ and ${ }^{64} \mathrm{Cu}$ labeled RGD-based tracers exhibited highly sensitive and integrin $\alpha_{\mathrm{v}} \beta_{3}$ specific tumor uptake, desirable pharmacokinetics, pharmacodynamics and metabolic stability, as well as high tumor activity accumulation. We have recently demonstrated that graphical analysis of non-invasive PET imaging data allows quantification of tumor integrin expression level in vivo. All of the above features are crucial for clinical application of integrintargeted early lesion detection and targeted internal radiotherapy.

The dimeric RGD peptide tracer $\left[{ }^{18} \mathrm{~F}\right] \mathrm{FB}-$ $\mathrm{E}[\mathrm{c}(\mathrm{RGDyK})]_{2}$, which can be used to quantify integrin expression level, has high integrin $\alpha_{\mathrm{v}} \beta_{3}$ avidity in vitro and integrin specific tumor uptake in vivo $[25,53,54,60]$. Human dosimetry estimation based on animal biodistribution data predicts that this tracer could be safely used in human, which makes it a promising lead candidate for clinical translation.

The tetrameric RGD peptide $\mathrm{E}\left\{\mathrm{E}[\mathrm{c}(\mathrm{RGDfK})]_{2}\right\}_{2}$, when labeled with ${ }^{64} \mathrm{Cu}$ through DOTA chelator, showed very high integrin avidity and good metabolic stability in the blood stream.[59] The overall high and prolonged tumor retention and rapid liver and kidney clearance result in good tumor to normal organ ratios, which not only makes it suitable for early lesion 
detection but also renders it great potential for integrin-targeted radiotherapy. Since DOTA is a universal chelator capable of forming stable complexes with various radiometals such as ${ }^{111} \mathrm{In}$, ${ }^{67 / 68} \mathrm{Ga},{ }^{86 / 90} \mathrm{Y},{ }^{64 / 67} \mathrm{Cu}$ and ${ }^{177} \mathrm{Lu}[61-64]$, the same conjugates developed in this project will have widespread applications for both radionuclide imaging and receptor-mediated internal radiotherapy.

Tumor integrin $\alpha_{v} \beta_{3}$ expression imaging is given as an example here to demonstrate how molecular imaging can provide a robust platform for understanding the mechanisms of tumor angiogensis and evaluating the efficacy of novel anti-angiogenic therapies. Further progress is needed to improve the sensitivity and resolution of molecular imaging technologies and to develop optimal molecular imaging probes as surrogate markers to pinpoint and monitor specific molecular and cellular actions of angiogenesis inhibitors As the molecular imaging probes get more and more specific which leads to visible signal only in the tumor or other targeted tissue, anatomical/functional imaging techniques is needed to identify the exact location of the signal. Multimodality molecular imaging techniques such as PET/CT (already in clinic) and SEPCT/CT are expected to play a major role in molecular imaging in the near future.

\section{Acknowledgments}

This work was supported, in part, by National Institute of Biomedical Imaging and Bioengineering (NIBIB) Grant R21 EB001785, Department of Defense (DOD) Breast Cancer Research Program (BCRP) Concept Award DAMD17-03-1-0752, DOD BCRP IDEA Award W81XWH-04-1-0697, DOD Prostate Cancer Research Program (PCRP) New Investigator Award (NIA) DAMD1717-03-1-0143, American Lung Association California (ALAC), the Society of Nuclear Medicine Education and Research Foundation, and National Cancer Institute (NCI) Small Animal Imaging Resource Program (SAIRP) R24 CA93862. The production of $\mathrm{Cu}-64$ at Washington University School of Medicine is supported by the NCI grant R24 CA86307.

\section{References}

[1] V. Brower, "Tumor angiogenesis-new drugs on the block", Nat. Biotechnol., 1999, vol. 17, pp. 963-8.

[2] G. Bergers and L. E. Benjamin, "Tumorigenesis and the angiogenic switch", Nat. Rev. Cancer, 2003, vol. 3, pp. 401-10.

[3] N. Ferrara, "VEGF and the quest for tumour angiogenesis factors", Nat. Rev. Cancer, 2002, vol. 2, pp. $795-803$.
[4] P. Nyberg, L. Xie, and R. Kalluri, "Endogenous inhibitors of angiogenesis", Cancer Res., 2005, vol. 65, pp. 3967-79.

[5] R. Kerbel and J. Folkman, "Clinical translation of angiogenesis inhibitors", Nat. Rev. Cancer, 2002, vol. 2, pp. 727-39.

[6] G. C. Tucker, " $\alpha_{\mathrm{v}}$ integrin inhibitors and cancer therapy", Curr. Opin. Investig. Drugs, 2003, vol. 4, pp. 722-31.

[7] R. K. Jain, "Normalization of tumor vasculature: an emerging concept in antiangiogenic therapy", Science, 2005, vol. 307, pp. 58-62.

[8] D. Hanahan and J. Folkman, "Patterns and emerging mechanisms of the angiogenic switch during tumorigenesis", Cell, 1996, vol. 86, pp. 353-64.

[9] M. Papetti and I. M. Herman, "Mechanisms of normal and tumor-derived angiogenesis", Am. J. Physiol. Cell Physiol., 2002, vol. 282, pp. C947-70.

[10] P. Friedl and K. Wolf, "Tumour-cell invasion and migration: diversity and escape mechanisms", Nat. Rev. Cancer, 2003, vol. 3, pp. 362-74.

[11] E. Sahai, "Mechanisms of cancer cell invasion", Curr. Opin. Genet. Dev., 2005, vol. 15, pp. 87-96.

[12] M. Egeblad and Z. Werb, "New functions for the matrix metalloproteinases in cancer progression", Nat. Rev. Cancer, 2002, vol. 2, pp. 161-74.

[13] T. Bogenrieder and M. Herlyn, "Axis of evil: molecular mechanisms of cancer metastasis", Oncogene, 2003, vol. 22, pp. 6524-6536.

[14] W. Guo and F. G. Giancotti, "Integrin signalling during tumour progression", Nat. Rev. Mol. Cell Biol., 2004, vol. 5, pp. 816-26.

[15] P. C. Brooks, R. A. Clark, and D. A. Cheresh, "Requirement of vascular integrin $\alpha_{V} \beta_{3}$ for angiogenesis", Science, 1994, vol. 264, pp. 569-71.

[16] C. C. Kumar, "Integrin $\alpha_{\mathrm{V}} \beta_{3}$ as a therapeutic target for blocking tumor-induced angiogenesis", Curr. Drug Targets, 2003, vol. 4, pp. 123-131.

[17] J. D. Hood and D. A. Cheresh, "Role of integrins in cell invasion and migration", Nat. Rev. Cancer, 2002, vol. 2, pp. 91-100.

[18] J. P. Xiong, T. Stehle, R. Zhang, A. Joachimiak, M. Frech, S. L. Goodman, M. A. Arnaout, B. Diefenbach, R. Dunker, and D. L. Scott, "Crystal structure of the extracellular segment of integrin $\alpha_{\mathrm{V}} \beta_{3}$ in complex with an Arg-Gly-Asp ligand", Science, 2002, vol. 296, pp. 151-5.

[19] H. Jin and J. Varner, "Integrins: roles in cancer development and as treatment targets", $\mathrm{Br}$. J. Cancer, 2004, vol. 90, pp. 561-565. P. C. Brooks, S. Stromblad, L. C. Sanders, T. L. von Schalscha, R. T. Aimes, W. G. StetlerStevenson, J. P. Quigley, and D. A. Cheresh, "Localization of matrix metalloproteinase MMP-2 to the surface of invasive cells by interaction with integrin $\alpha_{v} \beta_{3} "$, Cell, 1996, vol. 85, pp. 683-93.

[21] A. H. Schmieder, P. M. Winter, S. D. Caruthers, T. D. Harris, T. A. Williams, J. S. Allen, E. K. Lacy, H. Zhang, M. J. Scott, G. Hu, J. D. Robertson, S. A. Wickline, and G. M. Lanza, "Molecular MR 
imaging of melanoma angiogenesis with $\alpha_{V} \beta_{3^{-}}$ targeted paramagnetic nanoparticles", Magn. Reson. Med., 2005, vol. 53, pp. 621-27.

[22] X. Chen, P. S. Conti, and R. A. Moats, "In vivo near-infrared fluorescence imaging of integrin $\alpha_{\mathrm{V}} \beta_{3}$ in brain tumor xenografts", Cancer Res., 2004, vol. 64, pp. 8009-14.

[23] V. Beck, H. Herold, A. Benge, B. Luber, P. Hutzler, H. Tschesche, H. Kessler, M. Schmitt, H.G. Geppert, and U. Reuning, "ADAM15 decreases integrin $\alpha_{V} \beta_{3}$ /vitronectin-mediated ovarian cancer cell adhesion and motility in an RGD-dependent fashion", Int. J. Biochem. Cell Biol., 2005, vol. 37, pp. 590-603.

[24] X. Chen, R. Park, M. Tohme, A. H. Shahinian, J. R. Bading, and P. S. Conti, "MicroPET and autoradiographic imaging of breast cancer $\alpha_{\mathrm{V}^{-}}$ integrin expression using ${ }^{18} \mathrm{~F}$ - and ${ }^{64} \mathrm{Cu}$-labeled RGD peptide", Bioconjug. Chem., 2004, vol. 15, pp. 41-9.

[25] X. Chen, S. Liu, Y. Hou, M. Tohme, R. Park, J. R. Bading, and P. S. Conti, "MicroPET imaging of breast cancer $\alpha_{\mathrm{V}}$-integrin expression with ${ }^{64} \mathrm{Cu}$ labeled dimeric RGD peptides", Mol. Imaging Biol., 2004, vol. 6, pp. 350-9.

[26] T. F. Massoud and S. S. Gambhir, "Molecular imaging in living subjects: seeing fundamental biological processes in a new light", Genes Dev., 2003, vol. 17 , pp. 545-80.

[27] H. R. Herschman, "Molecular imaging: looking at problems, seeing solutions", Science, 2003, vol. 302, pp. 605-8.

[28] S. Gross and D. Piwnica-Worms, "Spying on cancer: molecular imaging in vivo with genetically encoded reporters", Cancer Cell, 2005, vol. 7, pp. $5-15$.

[29] A. E. Aplin, A. K. Howe, and R. L. Juliano, "Cell adhesion molecules, signal transduction and cell growth", Curr. Opin. Cell Biol., 1999, vol. 11, pp. 737-744.

[30] K. E. Gottschalk and H. Kessler, "The structures of integrins and integrin-ligand complexes: implications for drug design and signal transduction", Angew. Chem. Int. Ed. Engl., 2002, vol. 41, pp. 3767-74

[31] E. Ruoslahti, "RGD and other recognition sequences for integrins", Annu. Rev. Cell Dev. Biol., 1996, vol. 12, pp. 697-715.

[32] J. P. Xiong, T. Stehle, B. Diefenbach, R. Zhang, R. Dunker, D. L. Scott, A. Joachimiak, S. L. Goodman, and M. A. Arnaout, "Crystal structure of the extracellular segment of integrin $\alpha_{\mathrm{V}} \beta_{3}$ ", Science, 2001, vol. 294, pp. 339-45.

[33] K. Meerovitch, F. Bergeron, L. Leblond, B. Grouix, C. Poirier, M. Bubenik, L. Chan, H. Gourdeau, T. Bowlin, and G. Attardo, "A novel RGD antagonist that targets both $\alpha_{\mathrm{V}} \beta_{3}$ and $\alpha_{5} \beta_{1}$ induces apoptosis of angiogenic endothelial cells on type I collagen", Vascul. Pharmacol., 2003, vol. 40 , pp. 77-89.
[34] R. Qiao, W. Yan, H. Lum, and A. B. Malik, "ArgGly-Asp peptide increases endothelial hydraulic conductivity: comparison with thrombin response", Am. J. Physiol., 1995, vol. 269, pp. C110-7.

[35] D. B. Ellegala, H. Leong-Poi, J. E. Carpenter, A. L. Klibanov, S. Kaul, M. E. Shaffrey, J. Sklenar, and J. R. Lindner, "Imaging tumor angiogenesis with contrast ultrasound and microbubbles targeted to $\alpha_{\mathrm{v}} \beta_{3}$ ", Circulation, 2003, vol. 108, pp. 336-41.

[36] D. A. Sipkins, D. A. Cheresh, M. R. Kazemi, L. M. Nevin, M. D. Bednarski, and K. C. Li, "Detection of tumor angiogenesis in vivo by $\alpha_{\mathrm{V}} \beta_{3}$-targeted magnetic resonance imaging", Nat. Med., 1998, vol. 4, pp. 623-6.

[37] W. Wang, S. Ke, Q. Wu, C. Charnsangavej, M. Gurfinkel, J. G. Gelovani, J. L. Abbruzzese, E. M. Sevick-Muraca, and C. Li, "Near-infrared optical imaging of integrin $\alpha_{v} \beta_{3}$ in human tumor xenografts", Mol. Imaging, 2004, vol. 3, pp. 34351.

[38] J. V. Frangioni, "In vivo near-infrared fluorescence imaging", Curr. Opin. Chem. Biol., 2003, vol. 7, pp. 626-34.

[39] M. L. Janssen, W. J. Oyen, I. Dijkgraaf, L. F. Massuger, C. Frielink, D. S. Edwards, M. Rajopadhye, H. Boonstra, F. H. Corstens, and O. C. Boerman, "Tumor targeting with radiolabeled $\alpha_{\mathrm{v}} \beta_{3}$ integrin binding peptides in a nude mouse model", Cancer Res., 2002, vol. 62, pp. 6146-51.

[40] X. Chen, Y. Hou, M. Tohme, R. Park, V. Khankaldyyan, I. Gonzales-Gomez, J. R. Bading, W. E. Laug, and P. S. Conti, "Pegylated Arg-GlyAsp peptide: ${ }^{64} \mathrm{Cu}$ labeling and PET imaging of brain tumor $\alpha_{\mathrm{V}} \beta_{3}$-integrin expression", J. Nucl. Med., 2004, vol. 45, pp. 1776-83.

[41] R. Haubner, W. A. Weber, A. J. Beer, E. Vabuliene, D. Reim, M. Sarbia, K. F. Becker, M. Goebel, R. Hein, H. J. Wester, H. Kessler, and M. Schwaiger, "Noninvasive visualization of the activated $\alpha_{v} \beta_{3}$ integrin in cancer patients by positron emission tomography and $\left[{ }^{18} \mathrm{~F}\right]$ galactoRGD", PLoS Med., 2005, vol. 2, pp. e70.

[42] S. S. Gambhir, "Molecular imaging of cancer with positron emission tomography", Nat. Rev. Cancer, 2002, vol. 2, pp. 683-93.

[43] V. Sharma, D. Luker Gary, and D. PiwnicaWorms, "Molecular imaging of gene expression and protein function in vivo with PET and SPECT", J. Magn. Reson. Imaging, 2002, vol. 16, pp. 33651.

[44] R. Haubner, H. J. Wester, U. Reuning, R. Senekowitsch-Schmidtke, B. Diefenbach, H. Kessler, G. Stocklin, and M. Schwaiger, "Radiolabeled $\alpha_{v} \beta_{3}$ integrin antagonists: a new class of tracers for tumor targeting", J. Nucl. Med., 1999, vol. 40, pp. 1061-71.

[45] R. Haubner, H. J. Wester, F. Burkhart, R. Senekowitsch-Schmidtke, W. Weber, S. L. Goodman, H. Kessler, and M. Schwaiger, "Glycosylated RGD-containing peptides: tracer for tumor targeting and angiogenesis imaging with 
improved biokinetics", J. Nucl. Med., 2001, vol. 42, pp. 326-36.

[46] R. Haubner, H.-J. Wester, W. A. Weber, C. Mang, S. I. Ziegler, S. L. Goodman, R. SenekowitschSchmidtke, H. Kessler, and M. Schwaiger, "Noninvasive imaging of $\alpha_{\mathrm{V}} \beta_{3}$ integrin expression using ${ }^{18} \mathrm{~F}$-labeled RGD-containing glycopeptide and positron emission tomography", Cancer Res., 2001, vol. 61, pp. 1781-5.

[47] R. Haubner, B. Kuhnast, C. Mang, W. A. Weber, H. Kessler, H. J. Wester, and M. Schwaiger, "[ $\left[{ }^{18} \mathrm{~F}\right]$ galacto-RGD: synthesis, radiolabeling, metabolic stability, and radiation dose estimates", Bioconjug. Chem., 2004, vol. 15, pp. 61-9.

[48] J. L. Sutcliffe-Goulden, M. J. O'Doherty, P. K. Marsden, I. R. Hart, J. F. Marshall, and S. S. Bansal, "Rapid solid phase synthesis and biodistribution of ${ }^{18} \mathrm{~F}$-labelled linear peptides", Eur. J. Nucl. Med. Mol. Imaging, 2002, vol. 29, pp. 754-9.

[49] M. Ogawa, K. Hatano, S. Oishi, Y. Kawasumi, N. Fujii, M. Kawaguchi, R. Doi, M. Imamura, M. Yamamoto, K. Ajito, T. Mukai, H. Saji, and K. Ito, "Direct electrophilic radiofluorination of a cyclic RGD peptide for in vivo $\alpha_{v} \beta_{3}$ integrin related tumor imaging", Nucl. Med. Biol., 2003, vol. 30, pp. 1-9.

[50] X. Chen, R. Park, A. H. Shahinian, M. Tohme, V. Khankaldyyan, M. H. Bozorgzadeh, J. R. Bading, R. A. Moats, W. E. Laug, and P. S. Conti, ${ }^{18}$ Flabeled RGD peptide: initial evaluation for imaging brain tumor angiogenesis", Nucl. Med. Biol., 2004, vol. 31, pp. 179-89.

[51] X. Chen, R. Park, Y. Hou, V. Khankaldyyan, I. Gonzales-Gomez, M. Tohme, J. R. Bading, W. E. Laug, and P. S. Conti, "MicroPET imaging of brain tumor angiogenesis with ${ }^{18} \mathrm{~F}$-labeled PEGylated RGD peptide", Eur. J. Nucl. Med. Mol. Imaging, 2004, vol. 31, pp. 1081-9.

[52] X. Chen, R. Park, A. H. Shahinian, J. R. Bading, and P. S. Conti, "Pharmacokinetics and tumor retention of ${ }^{125}$ I-labeled RGD peptide are improved by PEGylation", Nucl. Med. Biol., 2004, vol. 31, pp. 11-9.

[53] X. Chen, E. Sievers, Y. Hou, R. Park, M. Tohme, R. Bart, R. Bremner, J. R. Bading, and P. S. Conti, "Integrin $\alpha_{v} \beta_{3}$-targeted imaging of lung cancer", Neoplasia, 2005, vol. 7, pp. 271-9.

[54] X. Chen, C. Plasencia, Y. Hou, and N. Neamati, "Synthesis and biological evaluation of dimeric RGD peptide-paclitaxel conjugate as a model for integrin-targeted drug delivery", J. Med. Chem., 2005, vol. 48, pp. 1098-106.

[55] M. Mammen, S. Chio, and G. M. Whitesides, "Polyvalent interactions in biological systems: implications for design and use of multivalent ligands and inhibitors", Angew. Chem. Int. Ed. Engl., 1998, vol. 37, pp. 2755-94.

[56] J. Logan, "Graphical analysis of PET data applied to reversible and irreversible tracers", Nucl. Med. Biol., 2000, vol. 27, pp. 661-70.
C. J. Anderson, L. A. Jones, L. A. Bass, E. L. Sherman, D. W. McCarthy, P. D. Cutler, M. V. Lanahan, M. E. Cristel, J. S. Lewis, and S. W. Schwarz, "Radiotherapy, toxicity and dosimetry of copper-64-TETA-octreotide in tumor-bearing rats", J. Nucl. Med., 1998, vol. 39, pp. 1944-51.

[58] S. Pauwels, R. Barone, S. Walrand, F. BorsonChazot, R. Valkema, L. K. Kvols, E. P. Krenning, and F. Jamar, "Practical dosimetry of peptide receptor radionuclide therapy with (90)Y-labeled somatostatin analogs", J. Nucl. Med., 2005, vol. 46 Suppl 1, pp. 92S-8S.

[59] Y. Wu, X. Zhang, Z. Xiong, Z. Cheng, D. R. Fisher, S. Liu, and X. Chen, "MicroPET imaging of glioma $\alpha_{\mathrm{v}}$-integrin expression using ${ }^{64} \mathrm{Cu}-$ labeled tetrameric RGD eptide", J. Nucl. Med., 2005 , in press.

[60] X. Chen, M. Tohme, R. Park, Y. Hou, J. R. Bading, and P. S. Conti, "Micro-PET imaging of $\alpha_{\mathrm{V}} \beta_{3^{-}}$ integrin expression with ${ }^{18} \mathrm{~F}$-labeled dimeric RGD peptide", Mol. Imaging, 2004, vol. 3, pp. 96-104.

[61] D. C. Onthank, S. Liu, P. J. Silva, J. A. Barrett, T. D. Harris, S. P. Robinson, and D. S. Edwards, ${ }^{190} \mathrm{Y}$ and ${ }^{111}$ In complexes of a DOTA-conjugated integrin $\alpha_{v} \beta_{3}$ receptor antagonist: different but biologically equivalent", Bioconjug. Chem., 2004, vol. 15, pp. 235-41.

[62] J. Hoffend, W. Mier, J. Schuhmacher, K. Schmidt, A. Dimitrakopoulou-Strauss, L. G. Strauss, M. Eisenhut, R. Kinscherf, and U. Haberkorn, "Gallium-68-DOTA-albumin as a PET blood-pool marker: experimental evaluation in vivo", Nucl. Med. Biol., 2005, vol. 32, pp. 287-92.

[63] P. McQuade, Y. Miao, J. Yoo, T. P. Quinn, M. J. Welch, and J. S. Lewis, "Imaging of melanoma using ${ }^{64} \mathrm{Cu}$ - and ${ }^{86} \mathrm{Y}$-DOTA-ReCCMSH(Arg11), a cyclized peptide analogue of $\alpha-\mathrm{MSH}^{\prime}$, J. Med. Chem., 2005, vol. 48, pp. 2985-92.

[64] A. Schmitt, P. Bernhardt, O. Nilsson, H. Ahlman, L. Kolby, H. R. Maecke, and E. Forssell-Aronsson, "Radiation therapy of small cell lung cancer with

${ }^{177}$ Lu-DOTA-Tyr ${ }^{3}$-octreotate in an animal model", J. Nucl. Med., 2004, vol. 45, pp. 1542-8. 